\title{
Locking compression plate in humeral shaft nonunion: a retrospective study of 18 cases
}

\author{
Rajesh Govindasamy ${ }^{1 *}$, Ramkumar Gnanasundaram ${ }^{2}$, Saravanan Kasirajan ${ }^{1}$, \\ Fawas Thonikadavath ${ }^{1}$, Jeff W. Rajadurai ${ }^{1}$
}

\author{
${ }^{1}$ Department of Orthopaedics, Vinayaka Missions Medical College, Karaikal, India \\ ${ }^{2}$ Department of Orthopaedics, Saveetha Medical College, Chennai, India
}

Received: 27 July 2016

Accepted: 01 August 2016

\section{*Correspondence:}

Dr. Rajesh Govindasamy,

E-mail: drgrortho@yahoo.com

Copyright: ( $)$ the author(s), publisher and licensee Medip Academy. This is an open-access article distributed under the terms of the Creative Commons Attribution Non-Commercial License, which permits unrestricted non-commercial use, distribution, and reproduction in any medium, provided the original work is properly cited.

\begin{abstract}
Background: Humeral shaft nonunions are frequently seen in Orthopaedic practice. Osteosynthesis with bone grafting is the treatment of choice. Locking compression plate (LCP) is the latest implant used in treating them. We retrospectively evaluated the outcome of use of LCP in humeral shaft non-union resulted by both conservative management and following failed internal fixations.

Methods: Eighteen patients with nonunion of humeral shaft in which ten were treated by traditional bone setters and eight followed by failed internal fixation were included in these study. The mean duration of nonunion was 18.3 months (range 8-22). The mean follow up period was 18 months (range 12-26). The mean age of patients was 44.4 years (range 22-60). All patients underwent osteosynthesis with LCP and autologoous cortico-cancellous iliac crest graft. The outcome measures include radiographic assessment of fracture union and preoperative and postoperative function using modified constant and murley scoring system.

Results: All fractures united following osteosyntesis average time for union was 15 weeks (range 10-24). We did not have any delayed union or non-union. The complications were superficial infection $(n=1)$ and wound haematoma $(\mathrm{n}=1)$. Three patients with preoperative radial nerve palsy recovered at the end of four months. Functional evaluation using constant-murley score showed excellent result in 14, good in 3 and fair in 1. We did not have any poor results. Conclusions: LCP with cancellous bone grafting is a safe reliable option for all forms of humeral shaft nonunion. We recommend it.
\end{abstract}

Keywords: Humeral fractures, Nonunion, Internal fixation, Osteosynthesis, Plates

\section{INTRODUCTION}

Humeral shaft fractures include 3 to $5 \%$ of all fractures. ${ }^{1}$ Conservative management and open reduction internal fixation is the generally accepted method of treatment in adults. In modern era, even today patients still seek treatment from the traditional bone setters which results in nonunion. The incidence of nonunion of humerus has been as high as $15 \%$ of all humeral fractures. ${ }^{1}$ Nonunion of humeral shaft is a difficult problem to treat as it defies all attempts to obtain healing, Jones w et al, stated "Ironically, the treatment of recent fractures of shaft of the humerus being so easy, the treatment of ununited fractures is difficult and has threatened to be one of our greatest failures". ${ }^{2}$

Cast immobilization and bracing provides excellent results in over $90 \%$ of isolated humeral shaft fractures, but nonunion is a recognized complication. ${ }^{3}$ Nowadays, open reduction internal fixation either by intramedullary 
devices, plate fixation with dynamic compression plate (DCP) has increased the nonunion rate from 8 to13\%, it is primarily due to improper surgical techniques and poor selection of implants for a particular fracture pattern. ${ }^{4}$

Various modalities of treatment with various devices are dynamic compression plate, angled blade plates, wave plates with or without bone grafting either by an autograft or allograft applied either onlay or inlay technique is used. Locked intramedullary nails and ilizarov external fixator has also been used in the management of nonunion of humeral shaft fractures. ${ }^{4}$ Locking compression plate (LCP) is the latest device which is used now as it is an useful implant in nonunion with diffuse osteoporosis, nonunion with enlarged screw holes due to previous surgeries, nonunions with cortical thinning due to previous nails and gap nonunions. ${ }^{5,6}$

In this present study, we retrospectively evaluated the use of LCP in osteosynthesis of humeral shaft nonunion with bone grafting.

\section{METHODS}

In our retrospective study of 18 patients with humeral shaft nonunion treated between June 2012 and June 2015 at our tertiary care institution were reviewed. We defined humeral shaft nonunion in our study as no evidence of union after six month period. Humeral shaft is defined as the part of humerus that is two centimeter below the the surgical neck and three centimeter above the olecranon fossa. ${ }^{7}$ There were 12 males $(67 \%)$ and six female $(23 \%)$ patients. The mean age was 44.4 years (range 22-60). Right side was involved in ten $(56 \%)$ and left side in eight (44\%).

The cause of injury was road traffic injury in $12(67 \%)$ patients, fall from height in five $(28 \%)$ and one patient had an assault (5\%). Five (28\%) patients had nonunion at proximal third and middle third junction, ten $(56 \%)$ had nonunion at middle third of the humerus, three $(16 \%)$ patients had involvement of middle third distal third junction. Ten patients $(56 \%)$ were treated by traditional bone setters, eight $(44 \%)$ patients had some form of internal fixation, (nails $=2, \mathrm{LCP}=4, \mathrm{DCP}=2)$. The mean duration of nonunion was 18.3 months (range 8-22). In patients treated by traditional bone setters seven had atrophic type, two had gap nonunion, one had pseudoarthrosis. In patients with internal fixation, two had atrophic variety and six had hypertrophic variety.

Out of 18 patients, three had radial nerve palsy. To rule out the possibility of latent infection in preoperative period, investigations such as erythrocyte sedimentation rate (ESR), C-reactive protein (CRP) and complete blood counts were done. Anteroposterior, lateral and oblique radiographs of the nonunion was taken. All patients were taken up for surgery with informed written consent about the complications and the need of bone grafting.

\section{Operative technique}

The surgical approach was decided according to the site of nonunion. Anterolateral approach for upper and middle third and posterior approach for those in the distal third. Dissection was carried out to the nonunion site taking care to identify and to protect radial nerve by all means. In all three cases, with preoperative radial nerve palsy we found that in two cases radial nerve was encased in scar tissue and in one case it was beneath the plate. This was very carefully dissected and freed. The previous implant was removed and edges of nonunion ends were then debrided of all soft tissue and dissected back to the bleeding bone. Recanalization of the medullary canal was done in both fragments. Intraoperative swab were obtained in all cases.

In all cases, cortico-cancellous bone graft was harvested from the iliac crest. We did not use any fibular strut graft. The graft was filled intramedullary in both fragments and they were reduced and stabilized using LCP by following the proper principles of LCP. In most cases, we used $4.5 \mathrm{~mm}$ LCP with single plate in one case we used an additional $3.5 \mathrm{~mm}$ additional LCP and bone graft was added over the nonunion site. A minimum of eight cortices were purchased on either sides of the fracture and whenever a previous implant such as DCP were used, we used a longer LCP to provide additional purchase over a minimum of two cortices in each fragment.

The patients were put on intravenous antibiotics for three days and continued with oral antibiotics for five days. Suture removal was done at the end of 14 days. The limb was immobilized in an above elbow slab for four weeks following the surgery. Active shoulder and finger mobilization was commenced immediately. We followed the patients at two interval for the first month, radiographs were taken, plaster was removed at the end of four weeks. Assisted shoulder and elbow exercises were commenced immediately. Then the patients were followed up at monthly intervals till radiographic union and then every six months for a minimum period of one year. All three patients got recovered from radial nerve palsy at the end of fourth month.

The mean follow up period was 18 months (range 12-26). The functional outcome was done by using Modified Constant and Murley Scoring. ${ }^{8}$ The scoring was obtained before and after osteosynthesis and at each follow up. Successful union was defined as the appearance of bridging callous or bridging of the cortex with at least partial obliteration of the fracture site observed on anteroposterior and lateral radiographs.

The results were analyzed using statistical version for social science (Version 15). The association test was done using chi-square and the level of significance was $\mathrm{p}<0.05$. 


\section{RESULTS}

Eighteen patients with humeral shaft nonunion treated representing $20.2 \%$ of all patients with humeral fractures seen in our hospital over the study period. All fractures were closed and all fractures united unevenfully without need of any additional procedures. The average time to union was 15 weeks (range 10-24). The patients who took longer time for union were mainly those treated by traditional bone setters had time for union around 20 weeks. This was statistically significant at $\mathrm{p}<0.05$.

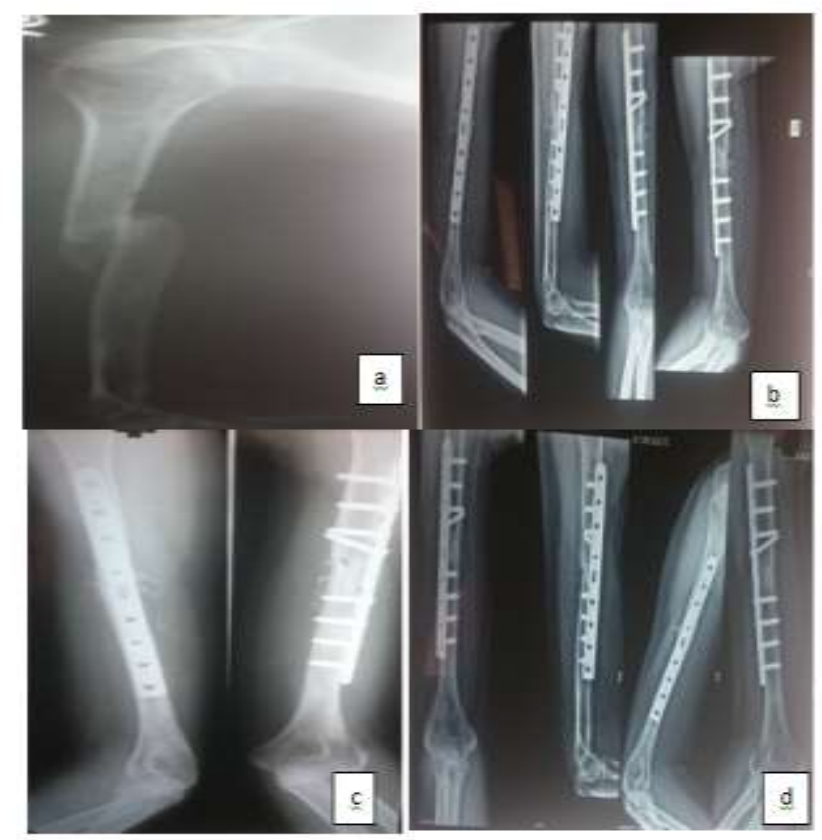

Figure 1: a) 34 year old male with atrophic nonunion, eight months following native treatment, b) immediate post-operative $x$-ray treated with lcp and bone graft, c) at the end of two months with union, d) at the end of four months with union.

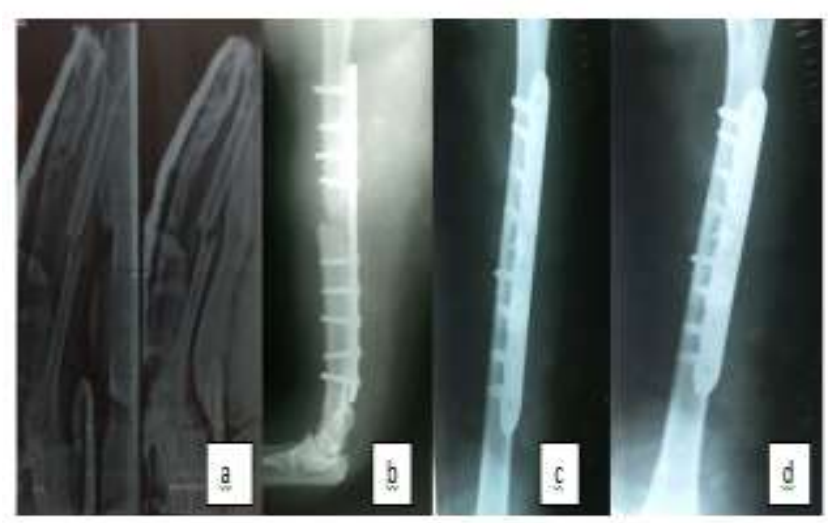

Figure 2: a) 40 year old female patient with nonunion, following conservative treatment, b) Immediate postoperative $x$ ray with $L C P, c)$ At the end of 2 months with union, d) At the end of 4 months with union.
We did not have any delayed union or nonunion in our study. We had one complication of superficial wound infection $(5 \%)$ and one with wound haematoma $(5 \%)$. Both this complications got settled with proper and timely intervention.

The mean constant-murley score was 13.75 in the preoperative period (range 0-30) and 77.50 (range 40-92) at the time of final follow up. Using the modified constant and murley scoring, fourteen (78\%) had excellent results (Case 1-Figure 1), three (16\%) had good results (Case 2-Figure 2) and one (6\%) had fair result (Case3-Figure 3). There were no patients with poor results.

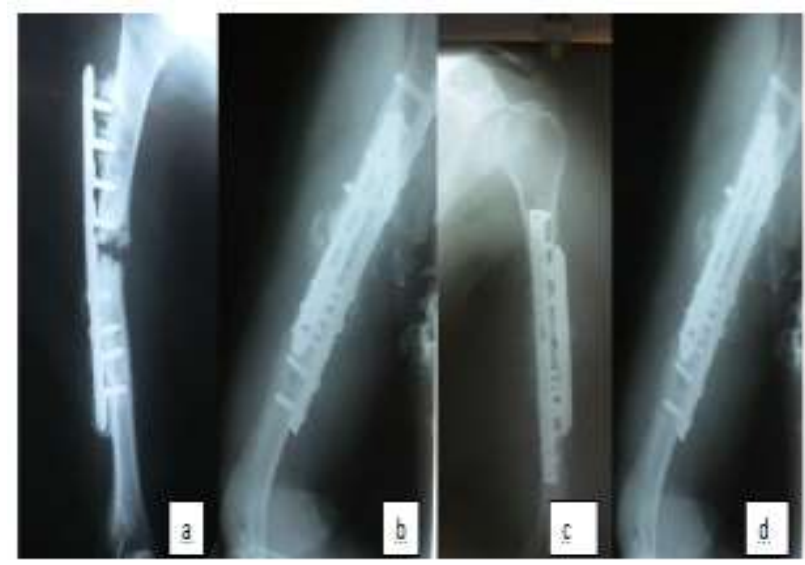

Figure 3: a) 30 year old male patient presented with nonunion and radial nerve palsy after treatment with poor technique LCP fixation, b) Immediate postoperative $x$-ray after fixation with $4.5 \mathrm{~mm}$ LCP and $3.5 \mathrm{~mm}$ LCP, c) At the end of 2 months with union, d) At the end of 4 months with union.

\section{DISCUSSION}

Treatment of nonunion of humeral shaft fractures continues to be a challenge to orthopaedic surgeons. Nonunion per se is a disaster to the patient as it affects the livelihood of the family. The reasons for nonunion is multifactorial, it may be patient related, surgeon related or depend upon the initial type of injury and treatment. ${ }^{9,10}$ The patient related factors may be older age, poor nutritional status, obesity, diabetes, alcoholism, use of corticosteroids, previous radiation, anticoagulation, fractures underlying burns and poor patient compliance. ${ }^{11}$

Other factors contributing to nonunion at the time of injury are open fractures with severe soft tissue injury and fractures with a transverse pattern. Treatment related complications are inadequate immobilization, soft tissue interposition, improper open reduction and fixation techniques with extensive periosteal stripping, and use of newer implants without following the correct principles of fixation. ${ }^{10,11}$ 
In our study, the most nonunion was observed in patients who had been previously treated with traditional bone setters. A traditional bone setter is alternative practitioners involved in the care of fractures. Studies have shown for several reasons patient continue to prefer treatment from them and only seek medical treatment when complications occur. ${ }^{12}$ Their mode of treatment includes use of local splints with leaves and bamboo sticks after a massage with the lack of knowledge in anatomy. These splints are usually two types affecting the blood supply of the limb which may results in gangrene and compartment syndrome. ${ }^{13}$ In these patients, the time for union time was longer than others.

In our study, we encountered nonunion cases treated with LCP, we retrospectively analyzed the method of fixation in them. It showed all screws holes were filled with locking screws, the surgeons did not follow the lag and lock principles in them and plate screw density was greater than 0.5 . So the surgeons should have avoided these complications if the basic fixation principle was adequately followed. We also encountered nonunion in cases treated with intramedullary devices and DCP, all this were due to poor fixation techniques.

Primary radial nerve palsy occurred in $17 \%$ of the patients, this finding was similar to the report to Tsai et al.14 In two cases, during open reduction the nerve was found adherent in the scar. This is probably due to closeness of the proximal part of the radial nerve in the radial groove making it vulnerable to injury. In one case, the nerve was found entrapped in the lower end of the plate, due to poor surgical technique. So during humeral fixation by either approach the surgeon should ensure the nerve is fully free and not get entrapped at the lower end of plate due to tight lateral intramuscular septum.

Surgical management is the treatment of choice in nonunion. Sound judgement must be exercised in choosing the type of surgical fixation in such cases. In established nonunions and nonunions with pseudoarthrosis the problem to obtain unions without disturbing the blood supply is not possible. Extensive periosteal stripping during this procedures result in further compromise in blood supply of this fragments and form a great hindrance in obtaining union. To make the surgical procedure successful the fragments must be adequately fixed and have an excellent osteogenic stimulus without disruption of blood supply to the nonunion site.

Various modalities had been used to treat nonunion historically, each has its own set of merits and demerits. DCP have been widely used in management of humeral shaft nonunion and have excellent union rates. But it can be applied only in nonunion that have been treated conservatively with reasonable bone quality and without any implants in-situ at the time of osteosynthesis. ${ }^{15-18}$
Locked intramedullary devices also have been used, but have high failure rates in this devices, which has been attributed to the absence of cyclical loading due to weight bearing and higher amounts of distractive and torsional loads on the humerus. These devices have higher complication rates including persistent pain in the shoulder, subacromial impingement, rotator cuff injury iatrogenic fracture comminution during nailing and radial nerve palsy. ${ }^{19}$

Ilizarov fixation has been used by several authors as it has a distinct advantage over other internal fixation modalities as it can be used in nonunion with infections. The disadvantages are bulky implant, pin tract infection, painful impingement of the frame on the chest wall and possibility of neurovascular injury due to improper

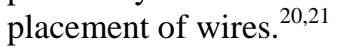

LCP has a unique advantage as it can be used in the treatment of nonunion in patients with osteoporosis and in patients who had any form of internal fixation as the index procedure. Screw holes made previously by index procedure may interfere with the subsequent purchase of screws, but LCP can overcome this advantage. In most cases, we used only one $4.5 \mathrm{~mm}$ LCP. In one case, we used an additional $3.5 \mathrm{~mm}$ LCP for additional stability. In our study, we used autologous bone graft in all cases, which was harvested from the iliac crest and we applied the grafts intramedullarily and also by on-lay technique. We did not use any fibular grafts to avoid donor site morbidity. Studies have shown non vascularized fibular graft longer than $6 \mathrm{~cm}$ have shown decreases capacity for incorporation and healing. Vascularized fibular graft increases the complexity and cost of osteosynthesis. ${ }^{22}$

In our study, all patients treated with LCP and bone grafting achieved $100 \%$ union. Our results were similar to Ring et al and Kumar et al. ${ }^{23,24}$ We would like to highlight the use of LCP in younger patients as it has good outcome and patients can achieve higher activity levels with heavier demand on upper extremity function. LCP is useful in all levels of humeral shaft nonunion. Nadkarni et al have used LCP in two patients with nonunion with previously inserted nails. ${ }^{25}$ LCP seems to farewell even in presence of significant bone loss requiring strut grafts.

The weakness of our study was as it was retrospective and only allowed comparison between the functional status in the preoperative and postoperative period. We had only small sample size with absence of control group and we did not compare our study results with other methods of fixation of humeral shaft nonunion.

We conclude that LCP is safe and reliable in achieving union in patients belonging to any age group with any activity level, as it can be used at all levels of humeral shaft and it can give $100 \%$ union if sound judgment is exercised in choosing the surgical technique and application of LCP with proper principles with excellent 
osteogenic stimulus. We recommend the judicial use of LCP in treating humeral shaft nonunion.

\section{ACKNOWLEDGEMENTS}

Authors would like to thank all patients for their cooperation in study. We also thank Gnanasundaram R, Tiwari RK for typing the manuscript.

\section{Funding: No funding sources}

Conflict of interest: None declared

Ethical approval: Not required

\section{REFERENCES}

1. Ring D, Perey BH, Jupiter JB. The functional outcome of operative treatment of ununited fractures of the humeral diaphysis in older patients. J Bone Joint Surg Am. 1999;81:177-90.

2. Watson JR. Fractures and joint injuries. Edinburg, London, New York, Churchil Livingston.1955.

3. Sarmiento A, Zagorski JB, Zych GA, Latta LL, Capps CA. Functional bracing for the treatment of fractures of the humeral diaphysis. J Bone Joint Surg Am. 2000;82(4):478-86.

4. Wallny T, Sagebiel C, Westerman K, Wagner UA, Reimer M. Comparative results of bracing and interlocking nailing in the treatment of humeral shaft fractures. Int Orthop. 1997;21(6):374-9.

5. Ring D, Kleon P, Kadzielski J, Helfet D, Jupiter JB. Locking compression plates for osteoporotic nonunions of the diaphyseal humerus. Clin Orthop Relat Res. 2004;425:50-4.

6. Nadkarni B, Srivastav S, Mittal V, Agarwal S. Use of locking compression plates for long bone nonunions without removing existing intramedullary nail: review of literature and our experience. J Trauma. 2008:65:482-6.

7. Chao TC, Chou WY, Chung JC, Hsu CJ. Humeral shaft fractures treated by dynamic compression plates, ender nails and interlocking nails. Int Orthop. 2005;29(2):88-91.

8. Constant CR, Murley AH. A clinical method functional assessment of the shoulder. Clin Orthop Relat Res. 1987;214:160-4.

9. Foulk DA, Szabo RM. Diaphyseal humeral fractures: natural history and occurrence of nonunion. Orthopedics. 1995;18(4):333-5.

10. Healy WL, White GM, Mick CA, Brooker AF, Weiland AJ. Nonunion of the humeral shaft. Clin Orthop. 1987;219:206-13.

11. Zuckerman JD, Koval KJ. Fractures of the shaft of the humerus. In Rockwood and Green's Fractures in Adults,edited by Rockwood C.A. :Green D.P., Bucholz R.W; Heckman J.D. Fourth Edition. Philadelphia, Lippincott. 1996;1:1025-53.
12. Bickler SW, Sanno DB. Bone setter's gangrene. J Pediatr Surg. 2000;35(10):1431-3.

13. Ogunlusi JD, Oginni LM, Ikem IC. Normal leg compartment pressures in adult Nigerians using the whitesides method. Iowa Orthop J. 2005;25:200-2.

14. Tsai CH, Fong YC, Chen YH, Hsu CJ, Chang CH, Hsu HC. The epidemiology of traumatic humeral shaft fractures in Taiwan. Int Orthop. 2009;33(2):463-7.

15. Rubel IF, Kleon P, Campbell D, Schwartz M, Liew A, Myers E, et al. Ope reduction and internal fixation of humeral nonunions: a biochemical and clinical study. J Bone Joint Surg Am. 2002;84:1315-22.

16. Lin CL, Fang CK, Chiu FY, Chen CM, Chen TH. Revision with dynamic compression plate and cancellous bone graft for aseptic nonunion after surgical treatment of humeral shaft fracture. J Trauma. 2009;67:1393-6.

17. Hornicek FJ, Zych GA, Hutson JJ, Malinin TI. Salvage of humeral non-unions with onlay bone plate allograft augmentation. Clin Orthop Relat Res. 2001;386:203-9.

18. Hsu TL, Chiu FY, Chen CM, Chen TH. Treatment of non-union of humeral shaft fracture with dynamic compression plate and cancellous bone graft. J Chin Med Assoc. 2005;68:73-6.

19. Mckee MD, Miranda MA, Reimer BL, Blasier RB, Redmond BJ, Sims SH, et.al. Management of humeral non-unions after failure of intramedullary nails. J Orthop Trauma. 1996;10:492-9.

20. Lammens J, Bauduin G, Driesen R, Moens P, Stuyck J, Desmet L, et al. Treatment of the nonunion of the humerus using illizarov external fixator. Clin Orthop Relat Res. 1998;353:223-30.

21. Kiran M, Jee R. Ilizarov's method for treatment of nonunion of diaphyseal fracture of the humerus. Indian J Orthop. 2010;44:444-7.

22. Vidyadhara S, Vamsi K, Rao SK, Gnanadoss JJ, Pandian S. Use of intramedullary fibular graft:a novel adjunct to plating in the treatment of osteoporotic humeral shaft nonunion. Int Orthop. 2009;33;1009-14.

23. Ring D, Kleon P, Kadzielski J, Helfet D, Jupiter JB. Locking compression plates for osteoporotic nonunions of the diaphyseal humerus. Clin Orthop Relat Res. 2004;425:50-4.

24. Kumar MN, Ravindranath P, Ravishankar MR. Outcome of locking compression plates in humeral shaft nonunions. Indian $\mathbf{J}$ Orthopaedics. 2013;47(2):150-5.

25. Nadkarni B, Srivastav S, Mittal V, Agarwal S. Use of locking compression plates for long bone nonunions without removing existing intramedullary nail: review of literature and our experience. J Trauma. 2008:65:482-6.

Cite this article as: Govindasamy $\mathrm{R}$, Gnanasundaram $\mathrm{R}$, Kasirajan S, Thonikadavath F, Rajadurai JW. Locking compression plate in humeral shaft non-union: a retrospective study of 18 cases. Int J Res Orthop 2016;2:86-90 